\title{
EMPLOYMENT RESPONSE TO SUPPLY AND DEMAND SHOCKS UNDER ENVY IN WAGE FORMATION*
}

\author{
BY
}

DAVID DE LA CROIX

\section{INTRODUCTION}

The belief that sector-specific unions are influenced by the wages obtained by other unions in other sectors due to the presence of envy has been used mainly to support the empirical observation that wages are highly correlated among industries (see e.g. Mitchell (1980)). Wage envy (i.e. workers care about relative wages) may exist for instance because the immobility between labour markets prevents the workers from changing jobs in order to eliminate wage differentials. The interest of analysing segmented labour markets can be defended by the observation that there are very high differences in unemployment across regions, industries and skills and, above all, that these differences are persistent (see chapter 6 of Layard, Nickell and Jackman (1991) for a documentation about these persistent differences). This persistence suggests that, even in the long run, the labour market contains a lot of segmentation elements.

Envy in wage formation introduces externalities and strategic complementarity among unions leading to sub-optimal equilibria (Cooper and John (1988)). These externalities may generate non-desired inflation (as in Akerlof (1969) and the well-known Taylor and Fischer models), unemployment as in Gylfason and Lindbeck (1984b) and loss of competitiveness as in De la Croix (1993) and in the Scandinavian model of Aukrust (1977). This leads to the recognition that part of the current unemployment can be eliminated by improving the coordination between social actors (Jacobs and Janssen (1990)).

In this paper, we want to clarify the links between wage envy and the main determinants of sectorial employment. We present a general equilibrium multisector model with simple decentralized efficient bargains in order to answer the following questions: What is the impact of envy on employment and on its

* Rijksuniversiteit Limburg, FNRS and Université Catholique de Louvain. I would like to thank Franz Palm for valuable comments on an earlier draft. This paper benefitted also from discussions with Torben Andersen, Jacques Drèze and Henri Sneessens (without implying them in any mistake). The detailed comments of the anonymous referee contributed to a large extent to clarify the exposition of the model.

De Economist 142: 193-209, 1994.

(C) 1994 Kluwer Academic Publishers. Printed in the Netherlands. 
sectorial allocation? What is the link between union power, the intensity of envy and employment? What is the role played by envy on employment when a sector faces a 'real' demand shock (e.g. a change in the propensity to consume)?

The economy under consideration is divided into sectors in which a representative firm produces competitively ${ }^{1}$ a single consumption good. There is a large number of households deriving utility from the consumption of all goods and providing at some cost labour on markets which are sector-specific. There is for each sector a union whose objective function is derived from the indirect utility of the members who provide labour to that sector. An equilibrium for a sector is defined, given other sectors' variables, by efficient contracts about employment and wages obtained by the union-firm couple in the sector. An equilibrium for the entire economy is made of equilibria for each sector either assuming that wages are formed independently in the different sectors without envy (the no externality case) or assuming that the sectors' efficient contracts are obtained with respect to a reference wage derived from the average labour earning in the economy (the externality case).

The model has the following properties: in the absence of externalities, employment is a function of technology and households' disutility of work. With externalities, the interaction between sectors through wage formation diminishes employment and makes it sensitive to union power and relative demand in addition to technology and disutility of work.

\section{THE MODEL AND ITS ASSUMPTIONS}

Households: The economy is divided into $K$ sectors. In each sector $k$ there is a representative firm which behaves competitively on its product market and $l s^{k}$ workers supplying inelastically their workforce to this firm and buying consumption goods from all sectors. The utility function of the representative household $j$ is defined over the consumption goods $c_{j}^{k}$ and over leisure. The elasticity of substitution between the goods of different sectors is -1 . The utility function is separable in consumption and leisure. The marginal disutility of work, which is equal to the real reservation wage, is $r . l_{j}^{k}$ is the amount of work done by $j$ in the representative firm of sector $k$ and is equal to 0 or 1 .

The consumer problem is:

$$
\begin{aligned}
& \max _{c_{j}^{k}} U_{j}=\prod_{k=1}^{K}\left(\frac{c_{j}^{k}}{\alpha^{k}}\right)^{\alpha^{k}}-r l_{j}^{k} \quad \sum_{k=1}^{K} \alpha^{k}=1 \\
& \text { s.t. } I_{j} \leq \sum_{k=1}^{K} p^{k} c_{j}^{k}
\end{aligned}
$$

1 The assumption of perfect competition on the goods' market is made for simplicity; introducing imperfect competitive behaviour, through e.g. monopolistic competition, would not qualitatively change the results. This would simply bring an additional source of inefficiency in the economy. 
with

$$
\begin{array}{ll}
I_{j}=w^{k} l_{j}^{k}+d_{j} & \text { if employed } \\
I_{j}=\quad d_{j} & \text { if unemployed }
\end{array}
$$

Income $I_{j}$ includes wage income, if any, and capital income $d_{j}$, where

$$
d_{j}=\sum_{z=1}^{K} \theta_{j}^{z} F^{z}
$$

and is proportional to the shares $\theta_{j}^{z}$ of the representative firm of sector $z$ being in possession of household $j . F^{k}$ is the nominal profit of the firm of sector $k$ :

$$
F^{k}=p^{k} y^{k}-w^{k} l^{k}
$$

where $l^{k}$ is its labour input (there is no other input in the model) with

$$
l^{k}=\sum_{j=1}^{J} l_{j}^{k} \leq l s^{k}
$$

and $l s^{k}$ total labour supply to sector $k$. The first-order condition for consumption leads to demands for goods which are linear in income:

$$
c_{j}^{k}=\alpha^{k}\left[\frac{I_{j}}{p^{k}}\right]
$$

Unions: Following Jacobsen and Schultz (1990), we derive the utility of the union from the utility of its members. More precisely, the utility of the sector-specific union $V^{k}$ is obtained by summing up the indirect utilities of the members. Replacing (1) in the utility function and using $\Sigma_{k} \alpha^{k}=1$ we get the indirect utility $\bar{U}_{j}$ :

$$
\bar{U}_{j}=\frac{I_{j}}{p}-r l_{j}^{k} \quad \text { where } p=\prod_{k=1}^{K}\left(p^{k}\right)^{\alpha^{k}} .
$$

$p$ is the aggregate price index implied by the utility function. Assuming that all households $\left(l s^{k}\right)$ supplying their workforce to this sector are union members and using the definition of income, the utility of the union is:

$$
\sum_{j \in l s^{k}} \bar{U}_{j}=V^{k}=\left(\frac{w^{k}}{p}-r\right) l^{k}+\sum_{j \in l s^{k}} \frac{d_{j}}{p}
$$

The fall-back utility $\tilde{V}^{k}$, which is the status quo point in the bargaining process, is the income attainable in case of a breakdown in the negotiation. In this situation, 
there is no production, no labour income and no employment. Each household will simply enjoy its capital income coming from the other sectors (the fact that the profit of its own sector is zero is supposed to affect its capital income in a negligible way):

$$
\tilde{V}^{k}=\sum_{j \in l s^{k}} \frac{d_{j}}{p}
$$

The corresponding net utility of the union is:

$$
V^{k}-\tilde{V}^{k}=l^{k}\left(\frac{w^{k}}{p}-r\right)
$$

Let us assume that the real reservation wage is the sum of two elements:

1. The relative price of the work that can be done at home. If a worker can produce the same good at home as in the firm but with a less efficient technology, the price of homework is a function of the price of the sector to which the agent offers his labour force. If we assume for simplicity a linear technology for the work done at home, $y^{k}=\phi_{0} l^{k}$, with the constraint over $\phi_{0}$ that it is more technically efficient to produce within a firm, i.e. $\phi_{0} l s^{k}<\gamma\left(l s^{k}\right)^{\gamma}{ }^{2}$ then the income from homework for one worker is simply $\phi_{0} p^{k}$.

2. A portion $\phi_{1}$ of the real mean wage in the economy, $\tilde{w} / p$, which can also be called the reference wage. This simply means that, when households evaluate their gain from working, they compare the wage they would earn with a reference wage which is the average labour earning in the economy: at a given wage, if the other workers gain more, the household would more and more prefer to work elsewhere (but this is not possible) or to stay at home. This idea was already present in Dunlop (1944): Wage increases originating in one sector may be diffused because wage earners are determined to fare just as well as their associates. (...) The community of housewives, with the inevitable 'you are as good as the next fellow,' is not to be underestimated.

This assumption has to do with some 'rivalry' or 'envy' effect: the workers look at the other workers to evaluate their gain of reaching an agreement during the bargaining.

2 We assume there are two different technologies to produce the same good. However, we have to impose the rule that the firm's technology is more efficient than the home technology for any feasible level of employment in order to justify the interest of producing within a firm. 
Summing up the two elements, the real reservation wage is:

$$
r=\frac{\phi_{0} p^{k}+\phi_{1} \tilde{w}}{p}
$$

The net union utility is defined over employment and over the difference between the negotiated wage and a combination of the sectoral price and of the average wage in the economy ${ }^{3}$ :

$$
V^{k}-\tilde{V}^{k}=l^{k} \frac{w^{k}-\phi_{0} p^{k}-\phi_{1} \tilde{w}}{p}
$$

The parameter $\phi_{1}$ measures the intensity of the externality between unions. It will allow us to study the impact of the intensity of the externality on the equilibrium, including the special case where $\phi_{1}=0$ (no externalities).

Notice that the assumption of segmentation of the labour market across sectors is closely related to the one of envy. As noted by Andersen and Christensen (1989): 'In a world with local and skill-specific markets for labor, the mobility between labor markets (jobs or regions) depends to a large extent on relative wages that reflect the costs or gains from changing jobs. Keynes argues that "workers care about relative wages because of inmobility between labor markets, as this prevents them from changing jobs to eliminate wage differentials.'

Firms: The firm's production function uses labour with decreasing marginal returns:

$$
y^{k}=t^{k}\left(l^{k}\right)^{\gamma} \quad 0<\gamma<1
$$

where $t^{k}$ is a sector-specific productivity parameter. For simplicity $\gamma$ is assumed the same in the whole economy.

The Efficient Bargaining Outcome: In each sector, the union and the representative firm negotiate an efficient outcome (McDonald and Solow, (1981)), bargaining jointly to determine the nominal wage and the employment level. Using the asymmetric Nash bargaining solution, with $\beta^{k}$ being the parameter which weights the two objective functions in the Nash product and which is called 'union power,' and assuming a zero fall-back profit, the maximization problem is:

$$
\max _{w^{k}, l^{k}}\left[l^{k} \frac{w^{k}-\phi_{0} p^{k}-\phi_{1} \tilde{w}}{p}\right]^{\beta^{k}}\left[\frac{p^{k} y^{k}-w^{k} l^{k}}{p}\right]^{\left(1-\beta^{k}\right)}
$$

3 Note that, since unemployed workers receive the same income (here, nothing) as the strikers, the net utility of the union does not incorporate the utility of the unemployed, as is the case in insider models. The unemployed workers are a third party, all of the burden of externalities is on the unemployed. 
The agents take $\tilde{w}$ and $p$ as exogenous macroeconomic variables. The first-order conditions are standard (see e.g. Holmlund (1989)):

$$
\left\{\begin{aligned}
\frac{\partial y^{k}}{\partial l^{k}} & =\frac{w^{k}}{p^{k}} \frac{\gamma}{\beta^{k}+\left(1-\beta^{k}\right) \gamma} \\
w^{k} & =\left(1-\beta^{k}\right)\left(\phi_{0} p^{k}+\phi_{1} \tilde{w}\right)+\beta^{k} p^{k} y^{k} / l^{k}
\end{aligned}\right.
$$

with $\partial y^{k} / \partial l^{k}=y t^{k}\left(l^{k}\right)^{\gamma-1}$.

Equation (3) states that the marginal productivity of labour is lower than the real wage by a factor $\gamma /\left(\beta^{k}+\left(1-\beta^{k}\right) \gamma\right)$. If union power tends to zero, we retrieve the neo-classical result of equality between marginal productivity and real wage. Equation (3) can be rewritten as:

$$
\frac{y^{k}}{l^{k}}=\frac{w^{k}}{p^{k}} \frac{1}{\beta^{k}+\left(1-\beta^{k}\right) \gamma}
$$

showing that average labour productivity is a mark-up over the real wage.

Equation (4) states that the wage is an average of the worker's disutility of work and of the representative firm's labour productivity in value; the weights are a function of union power. The inclusion of the reference wage reflects the 'envy effect.' The presence of the reference wage in the bargaining function introduces a negative externality between unions; since the resulting wage is a positive function of the reference wage, we also have strategic complementarity between unions. Cooper and John (1988) make clear that both externalities and strategic complementarity are sufficient to generate sub-optimality. This formulation also shows why the rational behaviour of unions derived from household preferences does not force the union to require full compensation for inflation unless it assumes other unions to be fully compensated. ${ }^{4}$ Stated in real terms, the wage equation can be rewritten as:

$$
w^{k} / p=\left(1-\beta^{k}\right)\left(\phi_{0} p^{k} / p+\phi_{1} \tilde{w} / p\right)+\beta^{k} a^{k} p^{k} / p
$$

which shows that workers will ask for full compensation of aggregate inflation as long as $\tilde{w} / p$ and $p^{k} / p$ remain constant. What is important here, comparing our rivalry model with the one by Gylfason and Lindbeck (1984b), is that the weights of the two elements in (4) are a function of union power. If union power is high, the workers capture a higher part of the firm's added-value. If it is low, the wage is determined to a larger extent by the wages of the other sectors.

4 This model closely corresponds to the wage determination process described by Keynes where each labour group is restrained by the at least temporary fixity of the wages of the other labour group. 


\section{THE EQUILIBRIUM}

Let us first consider the sectorial equilibrium which is conditional to the variables of the other sectors.

A sectorial equilibrium $E^{k}$ is a vector $\left[p^{k}, w^{k}, y^{k}, c^{k}, l^{k}\right]$ which satisfies

$$
\begin{aligned}
c_{j}^{k} & =\frac{\alpha^{k}}{n^{k}}\left[\frac{\Sigma_{j} I_{j}}{p^{k}}\right] \\
y^{k} & =t^{k}\left(l^{k}\right)^{\gamma} \\
t^{k}\left(l^{k}\right)^{\gamma-1} & =\frac{w^{k}}{p^{k}}\left(\beta^{k}+\left(1-\beta^{k}\right) \gamma\right)^{-1} \\
\mathrm{w}^{k} & =\left(1-\beta^{k}\right)\left(\phi_{0} p^{k}+\phi_{1} \tilde{w}\right)+\beta^{k} p^{k} y^{k} / l^{k} \\
y^{k} & =\sum_{j=1}^{J} c_{j}^{k}
\end{aligned}
$$

at given $I_{j}$ and $\tilde{w}$. The last equation implies that prices are such that demand and supply are equal on the goods market.

A macroeconomic equilibrium $E$ is a set of $K$ sectorial equilibria $E^{k}$, and a scalar $\tilde{\text { w }}$ which satisfies:

$$
\tilde{w}=\sum_{k} \lambda^{k} w^{k}
$$

where $\lambda^{k}=l s^{k} / \Sigma_{z} l s^{z}$ is the size of sector $k$ in a percentage of the total labour market and where

$$
\sum_{j=1}^{J} I_{j}=\sum_{z=1}^{K} p^{z} y^{z}
$$

This last equation reflects the fact that total income equals total production. Equation (6) shows that the $E$ equilibrium is computed by assuming that the expectations about the reference wage $\tilde{w}$ are equal to the effective mean wage in the economy. Let us now solve the model for this class of equilibria.

To solve the model we will proceed in three steps. The first step allows us to determine a relation between the employment levels of the various sectors. This relation is derived by solving a system which includes (6) and (2)-(3)-(4). The derivation is presented in Appendix 1. The idea is that the combination of all the claims of unions and firms across sectors leads to a relation between the employ- 


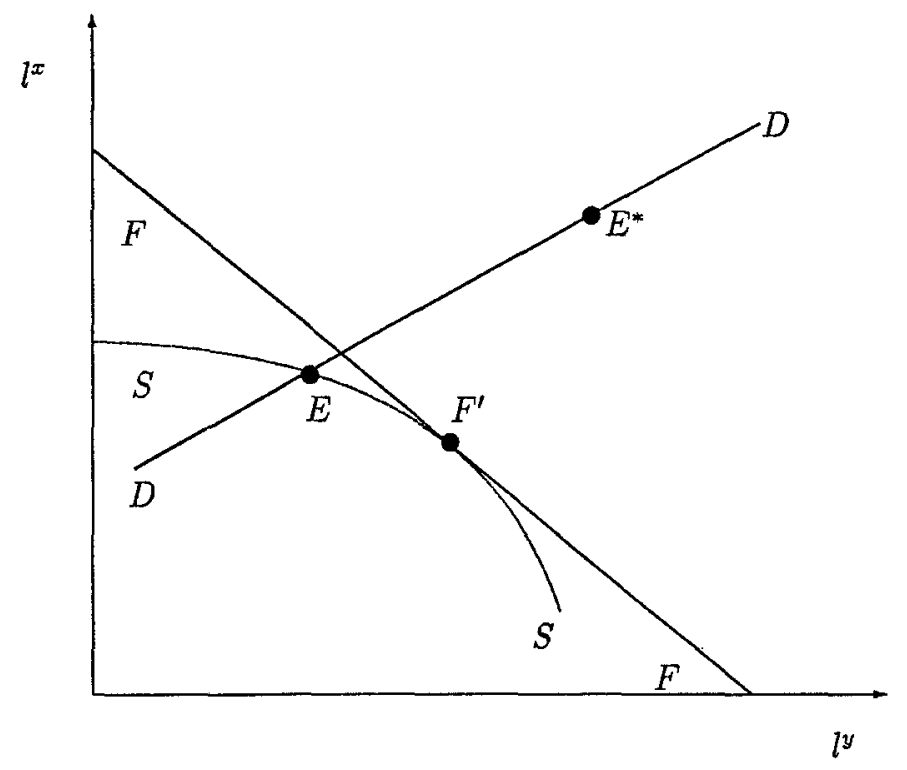

Figure 1 - The equilibria

ment levels of the different sectors. More precisely, this relation defines a trade-off between the employment levels of the different sectors. The mechanism of this trade-off is as follows. If output in sector $x$ falls, the wage in this sector also falls because of the employment rule (3). This decreases the reference wage for the other sectors, thus lowering their wage through their wage rule (4), which increases employment in these sectors. This supply relation, called $S S$, provides the complete set of $l^{k}$ combinations which makes compatibles all mark-up claims of the various firms and unions. It is given by:

$$
0=\sum_{k} \lambda^{k}\left[\frac{1}{\phi_{1}}-\frac{\left(1-\beta^{k}\right) \gamma+\beta^{k}}{\gamma t^{k}\left(l^{k}\right)^{\gamma-1}-\phi_{0}} t^{k}\left(l^{k}\right)^{\gamma-1}\right]
$$

Stated otherwise, (7) is a hypersurface in the $\left\{l^{k}\right\}$ space on which the economy has to stay in order to make the claims of all players compatible.

If $\phi_{1} \rightarrow 0$, (no externalities), (7) is sufficient to determine the equilibrium. In this case a macroeconomic equilibrium in the absence of externalities, denoted $E^{*}$, is characterized by:

$$
\begin{aligned}
& \lim _{\phi_{1} \rightarrow 0} l^{k}=\left[\frac{\phi_{0}}{\gamma t^{k}}\right]^{1 /(\gamma-1)} \\
& \lim _{\phi_{1} \rightarrow 0} \frac{w^{k}}{p^{k}}=\left[\beta^{k}+\gamma\left(1-\beta^{k}\right)\right] \frac{\phi_{0}}{\gamma}
\end{aligned}
$$


for all $k$. In this case, employment is only a function of technology and households' disutility of work. ${ }^{5}$

$S S$ and $E^{*}$ are drawn for the two-sector case in Figure 1. Note that $S S$ has an important property: total employment $\Sigma_{k} l^{k}$ varies when we move from one point of $S S$ to another. Figure 1 plots the iso-employment curve $\left(F F\right.$ curve) $\left(\Sigma_{k} l^{k}=\bar{l}\right)$ corresponding to the highest employment level compatible with $S S$. The tangency point $F^{\prime}$ is characterized by the higher employment level of $S S$.

The second step allows us to determine another set of relations between the employment levels of the various sectors. Using the demand equations ( 1 ) and the equality between demand and output in (5), we can compute pairwise ratios of demands:

$$
\frac{y^{x}}{y^{y}}=\frac{\alpha^{x} p^{y}}{\alpha^{y} p^{x}}
$$

Relative output is a function of the relative propensity to consume $\left(\alpha^{x} / \alpha^{y}\right)$ and of relative prices. From Appendix 2, using employment and wage equations, (10) implies that:

$$
\frac{\alpha^{y} t^{x}\left(l^{x}\right)^{\gamma}}{\alpha^{x} t^{y}\left(l^{y}\right)^{\gamma}}=\frac{\gamma t^{x}\left(l^{x}\right)^{\gamma-1}-\phi_{0}}{\gamma t^{y}\left(l^{y}\right)^{\gamma-1}-\phi_{0}}
$$

This equation defines a positive relationship between the employment levels of any two sectors. It is independent of $\phi_{1}$ because $\phi_{1}$ is the same in all sectors. In a $K$-sector economy, there are $K-1$ relations of type (11), called $D D$ relations. These positive relationships between employment of two sectors can be interpreted in the following way: if the output in one sector increases, the output in the other sector has to increase in order to keep the budget shares constant. The intersection of these $D D$ relations gives a curve in the $\left\{l^{k}\right\}$ space. In the two-sector case, we only have one relation which is drawn as the $D D$ curve in Figure 1.

Note that in the absence of externalities, the equilibrium value of $l^{k}$ defined in (8) satisfies (11), implying of course that all $D D$ relations do pass through $E^{*}$.

Third, the equilibrium vector $\left\{l^{k}\right\}$ at $E$ is given by the intersection of the $D D$ relations (11) with $S S$ (7). Unfortunately, (7)-(11) do not yield a simple determination of the $l^{k}$ due to non-linearities. However, the differentiation of this system allows us to determine the sign of the effect of parameter changes on the $\left\{l^{k}\right\}$ vector. This differentiation is presented in Appendix 3 .

5 The fact that households' utility is linear in income is an important assumption since it allows the contract curve to be vertical in the $\{w, l\}$ space (employment is not a function of union power). In the presence of a concave indirect utility, the above unemployment rate would also be a (negative) function of union power. 


\section{COMPARATIVE STATICS}

Let us now first consider the effect of the externalities on the level of employment. From Appendix $3, \mathrm{~d} l^{k} / \mathrm{d} \phi_{1}<0$ : the $E$ equilibrium is less efficient than the $E^{*}$ equilibrium in the sense that aggregate output is lower and thus unemployment is higher:

Result 1. Employment is decreasing with the magnitude of externalities:

$$
\mathrm{d} l^{k} / \mathrm{d} \phi_{1}<0 \quad \forall k
$$

Figure 1 clearly shows the loss of efficiency due to the externalities. This is represented by the distance between $E^{*}$ and $E$, which is itself a function of the position of $S S$. If $\phi_{1} \rightarrow 0, S S$ moves closer to $E^{*}$ and employment is higher in all sectors. If $\phi_{1}$ increases, $S S$ moves south-west and employment decreases. Note that there is a maximum limit for $\phi_{1}$ beyond which the condition that the wage has to be higher than the disutility of work $w^{k}>\phi_{0} p^{k}+\phi_{1} \tilde{w}$ is violated. In that case there is no production and no employment.

Result 1 is relatively obvious; it is a simple consequence of the sub-optimality of equilibria with (non-internalized) externalities. The two following results concerning the role of union power and the one of demand are quite more interesting.

Concerning the interrelation between union power, externalities and employment, we have in Appendix 3, $\mathrm{d} l^{k} / \mathrm{d} \beta^{z}<0 \forall k, z$ only if $\phi_{1}$ is non-zero. Therefore:

Result 2. In the presence of externalities, employment is decreasing with union power:

$$
\mathrm{d} l^{k} / \mathrm{d} \beta^{z}<0 \forall k, z \quad \text { if } \quad \phi_{1}>0
$$

Graphically, from (7), a rise in $\beta^{k}$ has to be compensated for by a drop in $l^{k}$ (at given $l^{j}, j \neq k$ ). This shifts $S S$ to the south-west.

From the literature (see Cahuc and Zylberberg (1991), Jacobs and Janssen (1990), and Gylfason and Lindbeck (1984a)) we know that, in the presence of externalities, decentralized bargaining leads to a sub-optimal equilibrium. However, the link between union power and this sub-optimality has not been made explicit. Therefore, Result 2, although intuitive, is important. Note also that the negative relationship between employment and union power predicted by Result 2 is in opposition with the usual positive relation between union power and employment implied by efficient contracts. ${ }^{6}$ This difference is due to the presence of

6 A usual critique that has been addressed to efficient bargaining models is that they imply in general a positive relation between union power and employment, which seems unacceptable to many. Contrary to this traditional literature, in our multi-sector framework with externalities, we find a negative relationship between union power and employment even in the presence of efficient bargaining. 
externalities and the underestimation by the agents of the effect of a wage increase on employment. ${ }^{7}$

Moreover, Result 2 implies that a rise in union power in one sector contaminates the other sectors by increasing their wage and lowering their employment level. The shift of $S S$ on Figure 2 implies a drop in all $l^{k}$ in order to have the same demand allocation schedule as defined by the $D D$ relations (which are not affected by union power). Figure 2 shows the effect of a rise in $\beta^{x}$ for the two-sector case: the shift from $E$ to $E^{\prime}$ characterizes the decrease of employment in all sectors.

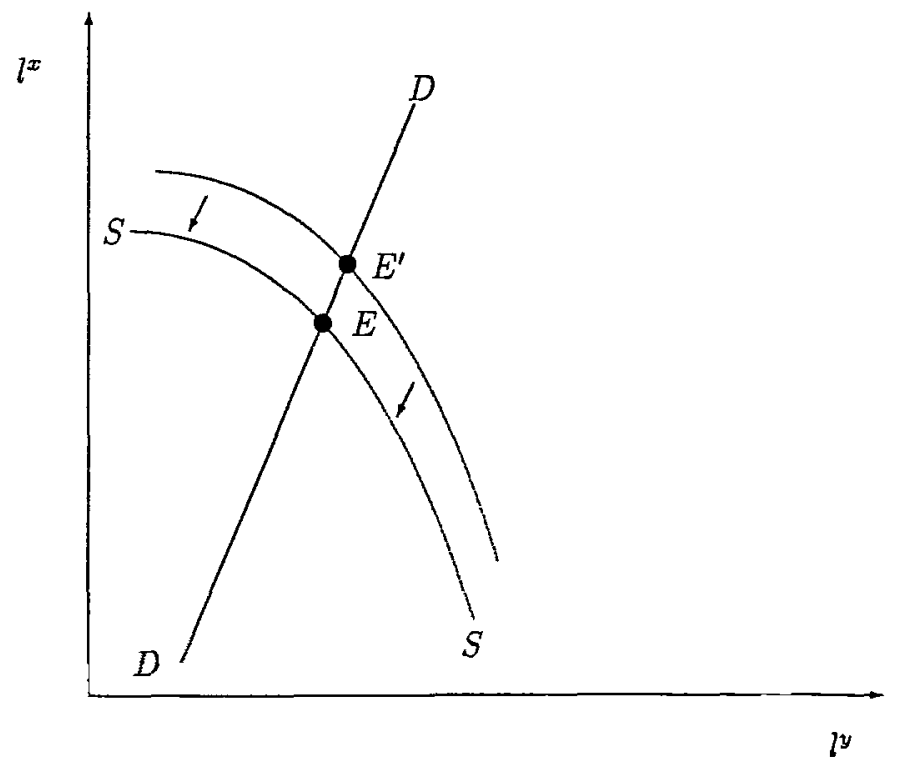

Figure 2 - Union power and employment

The presence of externalities allows for a role of demand through relative changes. In the presence of externalities, from Appendix $3, \mathrm{~d} l y / \mathrm{d}\left(\alpha^{x} / \alpha^{y}\right)<0$. This is true as long as $\phi_{1} \neq 0$ : if $\phi_{1} \rightarrow 0, \mathrm{~d} l^{y} / \mathrm{d}\left(\alpha^{x} / \alpha^{y}\right) \rightarrow 0$.

Result 3. Changes in the ratio $\alpha^{x} / \alpha^{y}$ modify the allocation of employment across sectors in the presence of externalities:

$$
\mathrm{d} l^{k} / \mathrm{d}\left(\alpha^{k} / \alpha^{x}\right)>0 \forall k, x \text { if } \phi_{1}>0
$$

The economic intuition behind this result is the following: a change in relative demand implies a change in relative prices. As long as there are no externalities,

7 Note that, in our model, we have assumed the same $\phi_{1}$ for all sectors. If the $\phi_{1}$ 's were different, we would only need two non-zero $\phi_{1}^{k \prime s}$ to obtain Result 2 . 
the efficient bargaining outcome implies a proportional change in prices in order to keep the real variables unchanged. ${ }^{8}$ In the presence of externalities, this is no longer true. The change in prices will be less than proportional and will not completely offset the change in relative demand; part of the adjustment will be made through quantities: in the rising-demand sector, the price has to rise, but it will rise less because the wage in this sector is pulled downward by the falling wage in the falling-demand sector.

Graphically, $D D$ always passes through the $E^{*}$ point. Changes in the relative propensity to consume $\alpha^{x} / \alpha^{y}$ make $D D$ rotate with the $E^{*}$ point as a fixed point (see Figure 3). This implies that the redistribution of activities from one sector to another is larger if $S S$ is located far from the fixed point.?

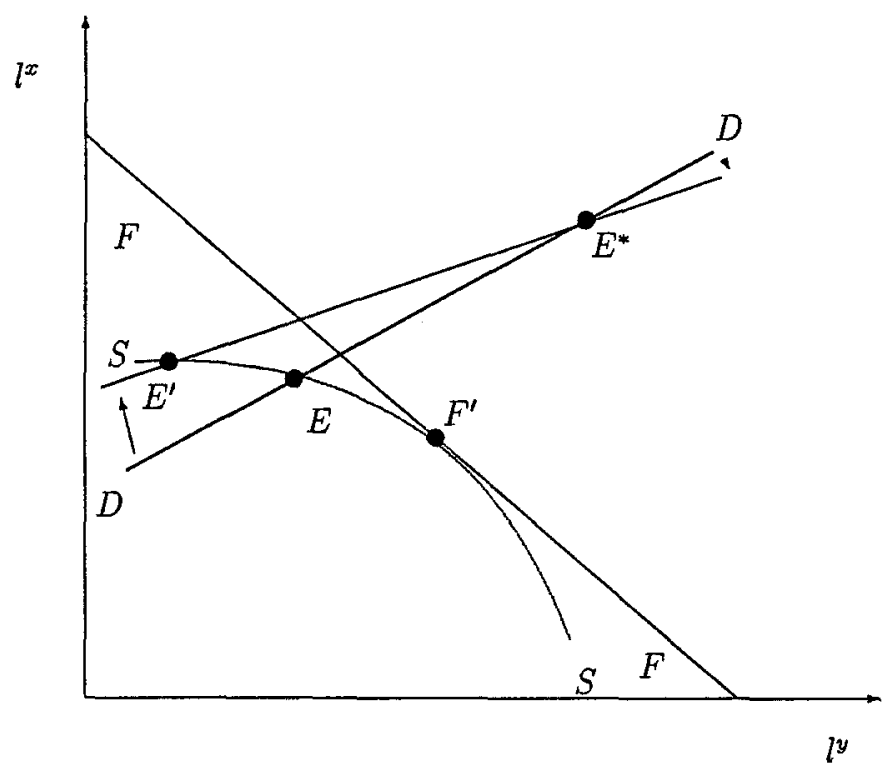

Figure 3 - Relative demand and unemployment

A corollary of Result 3 is that changes in any ratio $\alpha^{x} / \alpha^{y}$ affect total employment. Demand shifts may move the economy closer (or further) from point $F^{\prime}$ in Figure 3, which is the best point on $S S$ with respect to total employment. If an economy is located at point $F^{\prime}$, a shock which affects the relative demand implies

8 This is due to the fact that labour supply is inelastic.

9 In the two-sector model by Dixon (1988), we find something similar to Result 3. In his model, the government can increase employment by manipulating relative demand through its expenditure but its actions are limited to shifts along a kind of supply curve. However, Dixon does not make the link between the intensity of wage rivalry and the effectiveness of demand policy. 
employment losses at the macroeconomic level. ${ }^{10}$ Figure 3 illustrates a rise in $\alpha^{x} / \alpha^{y}$, moving the economy from $E$ to $E^{\prime}$ (a rise in $l^{x}$, a drop in $l^{y}$ ) and generating employment losses at the aggregate level since the iso-employment line passing through $E^{\prime}$ is lower than the one passing through $E$.

A crude application of this mechanism to the story of European unemployment could be the following. The drop in world demand after the first oil shock generated a negative sectorial demand shift for manufacturing sectors. Since the wages in these sectors are partly aligned with the wages in the service sectors (due to a rivalry effect materialized $e . g$. in an indexation mechanism), the price adjustment cannot fully absorb the shock so that employment falls in manufacturing sectors and rises in service sectors. The net effect could be negative.

Since the allocation of aggregate demand across sectors affects employment, sectorial demand policies may be used to fight unemployment by counterbalancing the negative shocks. Two instruments are a priori possible: the structure of indirect taxes and the sectorial allocation of government expenditures.

Note, finally, that a productivity increase in sector $k$ induces employment increases in this sector and has no effect on the other sectors when there are no externalities. In the presence of externalities, the effect in the other sectors is undetermined: both the $S S$ and $D D$ curves are affected implying a positive shift in $l^{x}$ (due to $S S$ ) and a negative shift in $l^{x}$ (due to $D D$ ) whose net effect is undetermined.

The results of this comparative static section can be summarized in the following table:

TABLE 1 - DETERMINANTS OF EMPLOYMENT

\begin{tabular}{lllll}
\hline & $\begin{array}{l}\text { Disutility } \\
\text { of work } \phi_{0}\end{array}$ & $\begin{array}{l}\text { Productivity } \\
t^{k}\end{array}$ & $\begin{array}{l}\text { Union } \\
\text { power } \beta^{k}\end{array}$ & $\begin{array}{l}\text { Relative } \\
\text { demand } \alpha^{k} / \alpha^{*}\end{array}$ \\
\hline $\begin{array}{c}\text { No externalities }\left(\phi_{1}=0\right) \\
\quad \text { Sector } k\left(l^{k}\right)\end{array}$ & - & + & 0 & 0 \\
$\quad$ Elsewhere $\left(l^{x}\right)$ & - & 0 & 0 & 0 \\
Externalities $\left(\phi_{1}>0\right)$ & & & & \\
$\quad$ Sector $k\left(l^{k}\right)$ & - & + & - & + \\
$\quad$ Elsewhere $\left(l^{x}\right)$ & - & $?$ & - & - \\
\hline
\end{tabular}

In the no externality case, employment in a given sector $k$ is a function of productivity in this sector and of the constant term of the disutility of work. In the externality case, employment of a given sector $k$ is additionally affected by union power in all sectors (with a negative sign even though bargaining is efficient), by the productivity in the other sectors (with an undetermined sign) and by the relative average propensity to consume goods of this sector (with a positive sign).

10 For instance, a rise in $\alpha^{x} / \alpha^{y}$ in a two-sector model located at $F^{\prime}$ implies a rise in employment in sector $x$ which does not offset the drop in employment in sector $y$. 


\section{CONCLUSION}

We have presented a multi-sector general equilibrium model where wages and employment result from efficient bargaining between firms and unions at the sectoral level. We have analyzed the properties of the macroeconomic equilibrium, either assuming that wages are formed independently in the different sectors (the no externality case) or assuming that the sectors' efficient contracts are obtained with respect to a reference wage derived from average labour earnings in the economy (the externality case). This externality case displays very different results from the no externality case, since we incorporate the effect of the 'wage-wage' spiral. In this case, unions and firms are not able to internalize the fact that their reference wage is modified by the decision they take, thereby introducing a source of inefficiency. In the absence of externalities, efficient bargaining generates an employment level which is only a function of a firm's technology and of the constant disutility of work of households. In the presence of externalities, employment is lower, and is decreasing with the magnitude of externalities and with union power. Contrary to the traditional literature, we find a negative relationship between union power and employment. This is due to the underestimation by the agents of the effect of a wage increase on employment. Sectorial demand shocks modify the allocation of output across sectors only in the presence of externalities; this reallocation of output may increase or decrease employment depending on the initial situation of the economy.

\section{APPENDICES}

\section{APPENDIX 1: DERIVATION OF $S S$}

Putting (4) into (6), we obtain the reference wage as a function of prices:

$$
\tilde{w}=\frac{\Sigma_{k} \lambda^{k}\left(\beta^{k} y^{k} / l^{k}+\left(1-\beta^{k}\right) \phi_{0}\right) p^{k}}{\left[1-\Sigma_{k} \lambda^{k} \phi_{1}\left(1-\beta^{k}\right)\right]}
$$

Replacing $y^{k} / l^{k}$ in (3) by its value in (4), we express the prices as a function of the reference wage:

$$
p^{k}=\frac{\phi_{1}}{\gamma y^{k} / l^{k}-\phi_{0}} \tilde{w}
$$

Solving now the system of the last two equations, and using $y^{k} / l^{k}=t^{k}\left(l^{k}\right)^{\gamma-1}$ we get:

$$
0=\sum_{k} \lambda^{k}\left[\frac{1}{\phi_{1}}-\frac{\left(1-\beta^{k}\right) \gamma+\beta^{k}}{\gamma t^{k}\left(l^{k}\right)^{\gamma-1}-\phi_{0}} t^{k}\left(l^{k}\right)^{\gamma-1}\right]
$$

which is called $S S$. 
APPENDIX 2: DERIVATION OF $D D$

Using equation (1) and (5) we compute the pairwise ratio of demands:

$$
\frac{y^{x}}{y^{y}}=\frac{\alpha^{x} p^{y}}{\alpha^{y} p^{x}}
$$

Using equation (a) of Appendix 1, the price ratio can be written as:

$$
\frac{p^{y}}{p^{x}}=\frac{\gamma y^{x} / l^{x}-\phi_{0}}{\gamma y^{y} / l^{y}-\phi_{0}}
$$

We now compute the ratio of the two demands using this new price ratio:

$$
\frac{y^{x}}{y^{y}}=\frac{\alpha^{x}}{\alpha^{y}} \frac{\gamma y^{x} / l^{x}-\phi_{0}}{\gamma y^{y} / l^{y}-\phi_{0}}
$$

using $y^{k} / l^{k}=t^{k}\left(l^{k}\right)^{\gamma-1}$ we finally find:

$$
\frac{\alpha^{y} t^{x}\left(l^{x}\right)^{y}}{\alpha^{x} t^{y}\left(l^{y}\right)^{y}}=\frac{\gamma t^{x}\left(l^{x}\right)^{\gamma-1}-\phi_{0}}{\gamma t^{y}\left(l^{y}\right)^{\gamma-1}-\phi_{0}}
$$

which is one $D D$ relation linking together a pair of employment levels. We may find $K-1$ independent surfaces of this type.

APPENDIX 3: DIFFERENTIATION OF (7) AND (11)

Let us rewrite (7) as:

$$
0=\sum_{k} \lambda^{k}\left[\frac{1}{\phi_{1}}-\frac{\left(1-\beta^{k}\right) \gamma+\beta^{k}}{\gamma-\phi_{0} / t^{k} l^{k^{1-\gamma}}}\right]
$$

Differentiating $(7)^{\prime}$ leads to:

$$
\begin{aligned}
0= & \left(\sum_{k} \lambda^{k}\right) \mathrm{d} \phi_{1}+\phi_{1}^{2} \sum_{k} \frac{\lambda^{k}(1-\gamma)}{\gamma-\phi_{0} / t^{k} l^{k^{1-\vartheta}}} \\
& +\sum_{k} \lambda^{k} \frac{\left[\left(1-\beta^{k}\right) \gamma+\beta^{k}\right](1-\gamma) \phi_{0} / t^{k} l^{k-\gamma}}{\left[\gamma-\phi_{0} / t^{k} l^{k^{1-\gamma}}\right]^{2}} \mathrm{~d} l^{k}
\end{aligned}
$$


Differentiating each $D D$ leads to:

$$
\begin{aligned}
0= & -\frac{t^{x}\left(l^{x}\right)^{\gamma}}{t^{y}\left(l^{y}\right)^{\gamma}} \mathrm{d}\left(\alpha^{y} / \alpha^{x}\right)-\left[\frac{(1-\gamma) \gamma t^{x}\left(l^{x}\right) \gamma-2}{\gamma t^{y}\left(l^{y}\right)^{\gamma-1}-\phi_{0}}+\frac{\alpha^{y} t^{x}\left(l^{x}\right)^{\gamma-1}}{\alpha^{x} t^{y}\left(l^{y}\right)^{\gamma}}\right] \mathrm{d} l^{x} \\
& +\left[\frac{\gamma t^{x}\left(l^{x}\right)^{\gamma-1}-\phi_{0}}{\left[\gamma t^{y}\left(l^{y}\right)^{\gamma-1}-\phi_{0}\right]^{2}}(1-\gamma) \gamma t^{y}\left(l^{y}\right)^{\gamma-2}+\frac{\alpha^{y} t^{x}\left(l^{x}\right)^{\gamma}}{\left[\alpha^{x} t^{y}\left(l^{y}\right)^{y}\right]^{2}} \alpha^{x} t^{y}\left(l^{y}\right)^{\gamma-1}\right] \mathrm{d} l^{y}
\end{aligned}
$$

$\forall y=1 . . K, y \neq x$. Putting everything together, we find the signs of the variation of $l^{k}$ as a function of the variations of the parameters:

$$
\begin{aligned}
\mathrm{d} l^{k} / \mathrm{d} \phi_{1}<0 & \forall k \\
\mathrm{~d} l^{k} / \mathrm{d} \beta^{z}<0 & \forall k, z \text { if } \phi_{1}>0 \\
\mathrm{~d} l^{k} / \mathrm{d}\left(\alpha^{k} / \alpha^{x}\right)>0 & \forall k, x \text { if } \phi_{1}>0
\end{aligned}
$$

\section{REFERENCES}

Akerlof, G. (1969), 'Relative Wages and the Rate of Inflation,' Quarterly Journal of Economics, 83, pp. 353-374.

Andersen, T. and M. Christensen (1989), 'Relative Wages and Employment Fluctuations,' Journal of Macroeconomics, 11, pp. 477-492.

Aukrust, O. (1977), 'Inflation in the Open Economy: A Norwegian Model,' in: L. Krause and W. Salant (eds.), Worldwide inflation, The Brookings Institution, Washington DC.

Cahuc, P. and A. Zylberberg (1991), 'Niveaux de négociations salariales et performances macroéconomiques,' Annales d'Economie et Statistique, 23, pp. 1-12.

Cooper, R. and A. John (1988), 'Coordinating Coordination Failures in Keynesian Models,' Quarterly Journal of Economics, 53, pp. 441-463.

Dixon, H. (1988), 'Unions, Oligopoly and the Natural Range of Employment,' Economic Journal, 98, pp. 1127-1147.

de la Croix, D. (1993), 'Wage Interdependence and Competitiveness,' Recherches Economiques de Louvain, 59, pp. 395-426.

Dunlop, J. (1944), Wage Determination Under Trade Unions, New York.

Gylfason, T. and A. Lindbeck (1984a), 'Union Rivalry and Wages: An Oligopolistic Approach,' Economica, 51, pp. 129-139.

Gylfason, T. and A. Lindbeck (1984b), 'Competing Wage Claims, Cost Inflation, and Capacity Utilization,' European Economic Review, 24, pp. 1-21.

Jacobs, J. and M. Janssen (1990), 'Coordinating Unions, Wages and Employment,' De Economist, 138, pp. 321-339.

Jacobsen, H. and C. Schultz (1990), 'A General Equilibrium Macro Model with Wage Bargaining,' Scandinavian Journal of Economics, 92, pp. 379-398.

Holmlund, B. (1989), 'Wages and Employment in Unionized Economies: Theory and Evidence,' in: B.L. Holmlund, K.-G. Lofgren and L. Engstrom, Trade Unions, Employment, and Unemployment Duration, Oxford.

Keynes, J.M. (1936), The General Theory of Employment, Interest and Money, London.

Layard R., S. Nickell and R. Jackman (1991), Unemployment - Macroeconomic Performance and the Labour Market, Oxford. 
MacDonald, I. and R. Solow (1981), 'Wage Bargaining and Employment,' American Economic Review, 71, pp. 898-908.

Mitchell, D.B.J. (1980), Unions, Wages, and Inflation, Brookings Institution, Washington DC.

\author{
Summary
}

\title{
EMPLOYMENT RESPONSE TO SUPPLY AND DEMAND SHOCKS UNDER ENVY IN WAGE FORMATION
}

We analyse the impact of wage envy on employment and on its sectorial allocation. A multi-sector general equilibrium model in which externalities among sectors arise through wage envy and decentralized bargaining is presented. In the no externality case, sectorial employment is a function of sectorial productivity and of the disutility of work. In the externality case, sectorial employment is additionally affected by union power in all sectors (with a negative sign even though bargaining is efficient), by the productivity in the other sectors (with an undetermined sign) and by the relative average propensity to consume goods of this sector (with a positive sign). 